\title{
Novel Immunological and Therapeutic Insights in Guillain-Barré Syndrome and CIDP
}

\author{
Luis Querol ${ }^{1,2}$ (1) . Cinta Lleixà ${ }^{1}$ \\ Accepted: 2 September 2021 / Published online: 21 September 2021 \\ (c) The American Society for Experimental NeuroTherapeutics, Inc. 2021
}

\begin{abstract}
Summary
Inflammatory neuropathies are a heterogeneous group of rare diseases of the peripheral nervous system that include acute and chronic diseases, such as Guillain-Barré syndrome (GBS) and chronic inflammatory demyelinating polyradiculoneuropathy (CIDP). The etiology and pathophysiological mechanisms of inflammatory neuropathies are only partly known, but are considered autoimmune disorders in which an aberrant immune response, including cellular and humoral components, is directed towards components of the peripheral nerve causing demyelination and axonal damage. Therapy of these disorders includes broad-spectrum immunomodulatory and immunosuppressive treatments, such as intravenous immunoglobulin, corticosteroids, or plasma exchange. However, a significant proportion of patients do not respond to any of these therapies, and treatment selection is not optimized according to disease pathophysiology. Therefore, research on disease pathophysiology aiming to reveal clinically and functionally relevant disease mechanisms and the development of new treatment approaches are needed to optimize disease outcomes in CIDP and GBS. This topical review describes immunological progress that may help guide therapeutic strategies in the future in these two disorders.
\end{abstract}

Keywords Inflammatory neuropathies · Guillain-Barré syndrome $\cdot$ Chronic inflammatory demyelinating polyradiculoneuropathy $\cdot$ Immunomodulatory treatments

\section{Introduction}

Inflammatory neuropathies are a heterogeneous group of rare diseases of the peripheral nervous system. They are characterized by combinations of motor and sensory symptoms that cause significant disability and that generally improve with immunomodulatory and immunosuppressive treatments. The diagnosis of these diseases is based on clinical, electrophysiological, and laboratory testing criteria [1].

The etiology and pathophysiological mechanisms of inflammatory neuropathies are only partly known, but humoral and cellular immunity are likely playing a role in their pathogenesis. Autoantibodies against peripheral nerve molecules such as gangliosides or proteins of the Ranvier node have been described, allowing the identification of

\section{Luis Querol}

lquerol@santpau.cat

1 Neuromuscular Diseases Unit, Department of Neurology, Hospital de La Santa Creu I Sant Pau, Universitat Autònoma de Barcelona, Mas Casanovas 90, 08041 Barcelona, Spain

2 Centro Para La Investigación Biomédica en Red en Enfermedades Raras (CIBERER), Madrid, Spain subgroups of patients with specific clinical phenotypes [2]. Even though the exact mechanisms underlying the development of immunopathology remain unknown, immunemediated neuropathies are considered treatable. The main challenge to successfully select immunotherapy is the great variability in the underlying pathobiology that leads to a variable clinical presentation and disease course, in the absence of biomarkers that inform treatment selection [3].

This review will focus in the two main inflammatory neuropathy categories, including the acute forms - GuillainBarré syndrome (GBS) and its variants - and the chronic sensory motor forms, grouped under the chronic inflammatory demyelinating polyradiculoneuropathy (CIDP) diagnostic category [4].

\section{Chronic Inflammatory Demyelinating Polyneuropathy (CIDP)}

CIDP is a rare immune-mediated neuropathy that predominantly appears in males and that associates with increasing age [5]. CIDP is usually characterized by slowly progressive, symmetric, proximal, and distal paresis and sensory 
dysfunction. Symptoms develop for over 2 months, and the course can be either progressive or relapsing [2]. CIDP patients have electrophysiological or pathological evidence of peripheral nerve demyelination and respond to immunosuppressive or immunomodulatory therapies [6].

Clinically, patients affected with CIDP can be classified by having a typical CIDP or a CIDP variant: typical CIDP is a symmetric sensory motor polyneuropathy affecting proximal and distal muscles and accounts for approximately $50 \%$ of CIDP cases (although in some series typical CIDP may be as high as 80\%) [7]. Clinical presentations different from typical CIDP are considered CIDP variants that include distal, multifocal, focal, motor, or sensory CIDP $[8,9]$. Whether clinical variability correlates with underlying pathobiological variability is not clear, since patients with CIDP variants may evolve into typical CIDP over time. However, the description in a recent study that a significant proportion of patients remain classified as a CIDP variant for several years, added to the diverse response to therapy that display some of the clinical variants, suggests that diversity of pathogenic mechanisms may explain, at least in part, the appearance of CIDP variants [7]. Additional research is needed to understand if clinical variability is driven by pathobiological variability.

Although the immunological mechanisms underlying the disease are not well understood, it is considered an autoimmune disorder in which an aberrant immune response, including cellular and humoral components, is directed towards components of the peripheral nerve causing demyelination and axonal damage [6].

\section{Cellular Immunity}

Classical CIDP pathology is associated with macrophage and $\mathrm{T}$ cell infiltration in the peripheral nerves and nerve roots that results in segmental demyelination [10]. Histological studies in sural nerves from patients affected with CIDP found hypomyelination with immunoglobulin and complement deposition on the outer surface of Schwann cells and the compact myelin, onion bulb formation, abnormal Schwann cell morphology, and irregular paranodal loops [10]. However, these pathological findings are only present in a subset of patients, and most likely, different phenotypes associate with different immunopathological features [11].

It is unclear how blood-nerve (and blood-brain) barrier breakdown happens in CIDP, but, at least in animal models $[12,13]$, it is one of the first events in nerve inflammation and may be mediated by inflammatory molecules released by inflammatory cells in the peripheral immune compartment. This phenomenon, happening both in CIDP and GBS, may be activated by an autoimmune attack against the putative antigen or by other noxa, but it allows the access of autoantibodies, macrophages, and other immune mediators to the endoneurial space to cause to nerve damage [6].

Demyelination caused by macrophages has been proposed to play an important role in the pathogenesis of CIDP: macrophage infiltration of the nerves triggers myelin breakdown through phagocytosis [14, 15]. Indeed, pathological studies show an increase in macrophage clusters around endoneurial blood vessels in sural nerves from CIDP patients compared to controls [16]. Although the factors that trigger myelin phagocytosis by macrophages have not been identified yet, it has been suggested that the deposition of autoantibodies at peripheral nerve components may trigger the myelin destruction by macrophages via the recognition of immunoglobulin Fc portions or complement molecules activated by autoantibodies. This mechanism was observed in a patient with antibodies against the LM1 glycolipid [17]. Macrophage-induced demyelination could also be triggered by $\mathrm{T}$ cells or the abnormal recognition by resident macrophages of aberrant myelin epitopes in the peripheral nervous system [14, 18].

Activated circulating $\mathrm{T}$ lymphocytes, elevated serum levels of pro-inflammatory cytokines, and the presence of $\mathrm{CD} 4+$ and $\mathrm{CD} 8+\mathrm{T}$ cells infiltrating sural nerve biopsies suggest an important role for $\mathrm{T}$ cells in CIDP development as well [19]. Studies comparing active vs inactive CIDP showed that the frequency of Th (T helper) 17 cells was significantly higher in the peripheral blood mononuclear cell (PBMCs) and CSF of active CIDP in comparison with remitting CIDP or to other non-inflammatory neurological diseases (OND). Moreover, the number of these cells decreased progressively when CIDP patients achieved remission. In line with these observations, the levels of proinflammatory interleukin-17 (IL-17) in plasma were higher in the active CIDP than remitting CIDP or OND, suggesting that Th17 cells might have an important role in the evolution of CIDP [19]. Th17 cells are potent inducers of autoimmune diseases through the activation of inflammatory mediators, angiogenesis, and the induction of immune cell activation. In fact, elevated levels of Th17 cells have been associated with other inflammatory autoimmune diseases, such as multiple sclerosis or systemic lupus erythematosus [20,21] and could be important in CIDP pathogenesis as well.

The $\mathrm{T}$ cell receptor repertoire from peripheral $\mathrm{T}$ cells in CIDP patients appears expanded and skewed towards restricted clones, especially in $\mathrm{CD} 8+\mathrm{T}$ cells, suggesting a specific activation of this $\mathrm{T}$ cell subset in the peripheral blood of CIDP patients. This finding supports the existence of an antigen-specific role of T cells in CIDP that could be central in the pathophysiology of certain patient populations. Finally, Heming et al. have also shown an increase of natural killer T cells (NK cells) and CD8 + T cells in CSF of CIDP patients, further supporting the role of cytotoxic cell types in this disease [22, 23]. 


\section{Humoral Immunity}

Although the direct role of B cells in nerve pathology is unknown, B cell phenotypes are altered in CIDP. B cells from CIDP patients display reduced amounts of the inhibitory FcyRIIB immunoglobulin receptor on the surface of B cells from CIDP patients compared to healthy controls [24, 25]. Moreover, the cytokine B cell activating factor (BAFF) is elevated in the sera of CIDP patients relative to controls, suggesting again that maturation of B cells may be relevant for disease appearance or persistence [26].

However, the most relevant research regarding humoral immunity in CIDP has studied the frequency and role of autoantibodies. This field of research has recently been boosted by reports of CIDP patients in which IgG4 antibodies targeting proteins of the node of Ranvier associate with specific phenotypes. Detection of these autoantibodies has changed the understanding of pathogenesis and has supported the idea that the clinical heterogeneity of the autoimmune neuropathies in general (and CIDP in particular) is associated with immunopathological heterogeneity.

The nodes of Ranvier are critical structures for saltatory conduction of nerve impulses in myelinated nerve fibers. They are flanked by paranodal Schwann cell-axon junctions composed of three major proteins: contactin 1 (CNTN1) and contactin-associated protein 1 (Caspr1) on the axonal side and neurofascin 155 (NF155) on the terminal myelin loops. The nodal isoforms of neurofascin (NF140 and NF186) are axonal membrane proteins expressed at the nodes [27]. Antibodies targeting all these nodal and paranodal proteins have been detected in small subsets of CIDP patients sharing immunopathological mechanisms, clinical features, and treatment response. This has led to the appearance of the autoimmune nodopathy (AN) diagnostic category in the recent update of the European Academy of Neurology/ Peripheral Nerve Society CIDP diagnostic guidelines that includes the inflammatory neuropathies harboring antibodies against nodo-paranodal proteins $[8,28]$.

Interestingly, antibodies targeting these axo-glial proteins are predominantly (although not exclusively) of the IgG4 isotype that does not activate complement, has a low capacity to bind to Fc $\gamma$ receptors, and is considered anti-inflammatory. The mechanisms leading to this isotype predominance are unknown [29].

\section{Anti-NF155 Antibodies}

Around 5\% of patients meeting CIDP diagnostic criteria harbor serum antibodies against NF155. Clinical features that are associated with NF155 seropositivity include a younger onset (including adolescents and young adults), high amplitude and low-frequency tremor, sensory ataxia, and poor response to IVIg [6].
Although the predominant isotype is $\mathrm{IgG} 4$, IgM antibodies against NF155 have also been described in 5 CIDP patients. These patients presented, as those with IgG4 antiNF155 antibodies, with tremor and axonal damage in nerve biopsies [30, 31].

The pathogenic role of the anti-Nf155 IgG4 antibodies is supported by the fact that levels of anti-NF155 antibodies seem to fluctuate in conjunction with clinical symptoms (AN patients with higher titters of the antibodies present with a more severe disease) [32]. Moreover, Manso et al. found that patient-derived anti-NF155 IgG4 antibodies prevent paranodal formation when injected in $\mathrm{P} 0$ and $\mathrm{P} 4$ rats. Also, when adult rats were administered patient-derived anti-NF155 antibodies into the CSF, it led to weakness and nerve conduction abnormalities demonstrating their pathogenic potential [33].

In the case of anti-NF155 IgM antibodies, their pathogenic effect is supported by a study of $\mathrm{Ng}$ et al. that reported enhancement and prolongation of experimental autoimmune neuritis (EAN) in rats after injection of mouse anti-NF155 IgM, but not by injection of an isotype control [34]. Whether anti-NF IgM presents only at disease onset in anti-NF155 AN and then the isotype switch elicits an IgG4 response or anti-NF IgM persists during the course of the disease in patients with predominant anti-NF IgM needs more research [35].

Interestingly, electron microscopy examination of sural nerve biopsies in AN patients with anti-NF155 showed endoneurial edema, a slight reduction of myelinated fiber density due to axonal degeneration, changes in the paranodal architecture with loss of transverse bands and widening of myelin loops, and absence of inflammatory cellular infiltration [36]. Therefore, the pathological alterations underlying the neuropathy caused by these antibodies differ significantly from the classic concept of macrophage-mediated demyelination [14].

We also observed that there is a very strong association between the DRB $1 * 15$ allele of the human leucocyte antigen (HLA) class II gene and the presence of anti-NF155 antibodies, suggesting that the interplay between a genetic predisposition and other, unknown risk factors enables the development of anti-NF155 antibodies [37].

\section{Anti-CNTN1 Antibodies}

Anti-CNTN1 antibodies are found in approximately 2-4\% of patients fulfilling CIDP diagnostic criteria. These patients are also clinically distinct, with a rapid and aggressive onset of the symptoms, predominant involvement of motor fibers and axonal damage, and poor response to IVIg [6, 38]. Interestingly, up to $60 \%$ of patients present with nephrotic syndrome caused by IgG4 and CNTN1 deposition at the glomeruli [39]. 
Patient-derived anti-CNTN1 antibodies induce alterations of the paranodal architecture in in vitro models [40]. Moreover, in an in vivo model, passive transfer of human IgG4 anti-CNTN1 prevented the binding of the CNTN1/CASPR1 complex to NF155 and disrupted the node of Ranvier structure in the absence of complement and inflammatory cells. After intraneural injection, IgG4 anti-CNTN1 diffused into the paranode and induced progressive deterioration of the animal model [41].

In the anecdotal histological studies reported on antiCNTN1 + AN patients, some authors have observed high numbers of endoneurial macrophages and axonal degeneration and widening of nodes or Ranvier, again in the absence of classical macrophage-mediated demyelination [36].

Although anti-CNTN1 antibodies were described to be predominantly $\operatorname{IgG} 4$, patients with an acute onset neuropathy and anti-CNTN1 antibodies of the IgG3 isotype, in which, unlike in IgG4-mediated pathology, complement activation has a pathogenic role, have also been reported [42].

\section{Anti-Pan-Neurofascin Antibodies}

The nodal isoforms of neurofascin include the isoforms with 140 and $186 \mathrm{Kd}$ molecular weight. Antibodies targeting all three isoforms of neurofascin, but mainly directed towards the nodal isoforms, have been described in less than $2 \%$ of patients fulfilling CIDP diagnostic criteria. The associated phenotype in these patients is variable including sensory ataxia without tremor, aggressive phenotypes leading to tetraplegia, and association with other autoimmune disorders, including nephrotic syndrome. Autoantibodies may be IgG4 or IgG3, and patients may respond to IVIg or corticosteroids. Pathological reports are anecdotal, showing Schwann cell microvilli loss as the most specific feature [43]. Formal studies demonstrating pathogenicity of these autoantibodies have not been performed yet $[6,44,45]$.

\section{Anti-CASPR1/CNTN1 Complex Antibodies}

Autoantibodies against CASPR1 were first reported in two patients with inflammatory neuropathies: one CIDP patient with IgG4 antibodies and one GBS patient with IgG3 antibodies. Histological analysis showed paranodal disruption in skin biopsies from both patients and paranodal IgG deposits in their sural nerve biopsies [46]. Our group reported autoantibodies targeting the CASPR1/CNTN1 complex in one patient [38], and three more patients with IgG4 antibodies against the complex were also reported in an Italian cohort [47]. Moreover, Appeltshauser et al. reported two patients with acute onset neuropathy reacting against both CNTN1 and CASPR1 proteins separately. Interestingly, in one of these patients, the authors found an autoantibody subclass switch from IgG3 in the acute phase of the disease to
IgG4 in the chronic stage and a change in the target autoantibody (from CNTN1 and CASPR1 to CASPR1 alone) [48].

Recently, our group, in collaboration with others, has published a study analyzing the clinical and immunological characteristics of $15 \mathrm{AN}$ patients with antibodies against the CASPR1/CNTN1 complex. We observed that patients presented with a rapid onset neuropathy with cranial nerve involvement, early axonal damage, and poor response to IVIg demonstrated that these antibodies target primarily CASPR1 protein, but binding is stronger when CNTN1 is also present [49]. Pathogenicity of these autoantibodies remains to be confirmed.

\section{Other Autoantibodies and Soluble Mediators}

The resemblance of CIDP (and GBS) with the experimental autoimmune neuritis model triggered by myelin proteins suggested that P0, P2, and PMP22, classical inducers of neuritis, could be autoantigens. Antibody responses against myelin proteins have been reported in some CIDP patients [50]; however, other authors did not confirm these findings, and the clinical and pathogenic relevance of anti-myelin autoantibodies remains unclear [6].

Diverse anti-ganglioside antibodies have been reported in some CIDP cohorts, specially anti-LM1, anti-GM1, and anti-GD1b antibodies; so far, antibodies against LM1 are the only ones associated to specific clinical features such as ataxia, and GM1 and GD1b IgM associate with multifocal motor neuropathy and chronic ataxic neuropathies associated to disyalosil antibodies (CANDA/CANOMAD), respectively [51, 52]. Apart from that weak association, other meaningful clinical-immunological correlations with anti-ganglioside antibodies have not been established yet.

Also, according to published reports, more than $40 \%$ of CIDP patients show antibodies against components of myelinated nerves [51,53]. Within this group, patients who harbor well-characterized antibodies account for less than $10 \%$ of all patients. Therefore, additional antigenic targets remain to be characterized.

Finally, in peripheral nerves from CIDP patients, demyelination typically starts at the paranodes [54], and Schwann cells quickly aim to remyelinate the damaged segment. However, this remyelination is insufficient, and shorter internodes and thinner myelin appear [55]. Joshi et al. analyzed the capacity of Schwann cells to support axonal regeneration by transplanting human and rodent Schwann cells exposed to sera from CIDP patients in a rat model of chronic nerve denervation and concluded that pro-regenerative functions of Schwann cells were affected in CIDP. This Schwann cell dysfunction was mediated by cytokines and growth factors, suggesting that soluble molecules other than autoantibodies may also play a role in CIDP pathogenesis, but this pathophysiological hypotheses need to be confirmed [56]. 


\section{Treatment}

Standard treatment protocols in CIDP include the use of corticosteroids [57], intravenous or subcutaneous immunoglobulins (IVIg or SCIg) [58], and plasma exchange (PLEx) [59], with approximately $50-70 \%$ of the patients responding to each of these treatments [60]. Other immunosuppressant therapies (such as cyclosporine or cyclophosphamide) are also used as steroid-sparing agents or in anecdotal cases not responding to standard regimens. According to the recent update of the EAN/PNS CIDP diagnostic guidelines, "IVIg or corticosteroids should be considered in typical CIDP and CIDP variants in the presence of disabling symptoms; plasma exchange is similarly effective but may be less well tolerated and more difficult to administer" [8].

However, there are some subtle differences in the response to therapy depending on the CIDP variant: a better response to IVIg than to steroids has been reported in some series of patients with multifocal CIDP [61-63], and the new EAN/PNS guidelines also recommend the use of IVIg for motor CIDP, based on the observation that purely motor CIDP may not respond (or may even worsen) with corticosteroids [8]. Moreover, as stated before, AN patients with IgG4 autoantibodies do not respond well to the standard treatments, particularly to IVIg, but can show remarkable improvement after treatment with rituximab instead [64].

Currently, autoimmune nodopathy patients aside, treatment selection is based on availability, convenience, and cost; treatment optimization follows a trial/error algorithm (periodic withdrawal of IVIg, addition of corticosteroidsparing agents, treatment combinations) with the objective of using the lowest dose and frequency of treatment courses and avoid overtreatment as, consistently, $30 \%$ of patients may enter in remission and do not need continuous therapy. There are no biomarkers available to optimize therapeutic choices and disease monitoring, although research in biomarker discovery is starting to be developed [65].

\section{Intravenous Immunoglobulins (IVIg)}

IVIg is considered a first-line treatment for CIDP given its efficacy, the rapid effect, and the low frequency of side effects. The recommended initial IVIg dose is $2 \mathrm{~g} / \mathrm{kg}$; however, in patients needing long-term IVIg, treatment necessity has to be periodically reassessed, and doses and frequencies need to be individualized [60]. While complete remission after short-term therapy occurs in some patients, others require long-term therapy [66]. Data from clinical trials show that at least three courses of IVIg infusion are needed to confirm response to treatment [58]. About $85 \%$ of CIDP patients that initially respond to IVIg require maintenance treatment, some patients requiring it for decades. A recent study compared two different modalities in maintenance therapy with IVIg: more frequent lower doses or less frequent higher doses, and did not find any difference regarding the outcome and side effects between the 2 modalities [67]. Periodic IVIg withdrawal attempts (either immediate or using dose reduction protocols) is necessary to detect patients in remission and to avoid overtreatment, although a small risk for subjects not returning to their baseline needs to be taken in account [66].

Some studies have focused on deciphering the mechanism of action of IVIg. This treatment exerts anti-inflammatory activity in autoimmune neuropathies by Fc-dependent and Fab-dependent mechanisms including neutralization of autoantibodies, increased autoantibody catabolism through FcRN receptor saturation, inhibition of complement, modification of $\mathrm{FcR}$ expression, and correction of altered cytokine patterns [68]. IVIg impacts T cells, B cells, macrophages, and NK cells: IVIg responders have greater T cell responses against myelin proteins and an increased frequency of CD8 + effector memory T cells compared to non-responders; these increased $\mathrm{T}$ cell counts decrease after treatment [69]. Reduced Fc $\gamma$ RIIB receptor expression in B cells in CIDP patients is partly restored after IVIg treatment [24, 25]; IVIg treatment decreases the levels of the B cell activating factor (BAFF) in sera of CIDP patients [26]; and the percentage of NK cells in PBMCs and antibody-dependent cell-mediated cytotoxicity is significantly reduced following IVIg treatment [70]. However, patients with IgG4 antibodies to nodal/ paranodal proteins show poor response to IVIg. As major mediators of IVIg effect are inhibition of complement pathway and binding to the inhibitory Ig receptor, the characteristics of IgG4 antibodies may explain the poor response of IVIg in these patients [71].

\section{Subcutaneous Immunoglobulins (SClg)}

SCIg provide an alternative route of administration that may improve some of the challenges associated with intravenous administration of immunoglobulins. Recently, the PATH study confirmed the efficacy of ScIg as maintenance therapy and provided evidence that SCIg is a safe, effective, and tolerable for CIDP patients [72,73].

This novel treatment is an effective option for CIDP patients, enabling treatment at home and reducing infusionrelated side-effects, although it does not provide a true therapeutic alternative in patients not responding to IVIg as it likely acts through the same therapeutic targets as IVIg.

\section{Corticosteroids}

Steroids are also effective for CIDP treatment (with a similar proportion of patients responding to them as to IVIg). They are used less frequently because they are associated 
with more side effects and less tolerance compared to IVIg, making them less suitable for long-term treatment, but in the context of IVIg shortage and increased cost, corticosteroids are the main therapeutic choice in medium- and low-income countries [74].

A retrospective study compared different regiments (daily oral prednisolone, pulsed oral dexamethasone, or pulsed intravenous methylprednisolone) in 125 patients with CIDP. Overall, $60 \%$ responded well to treatment, with no significant difference in safety and efficacy between the three treatment regimens. Corticosteroids led to CIDP improvement in $60 \%$ of patients and to remission in $61 \%$ of treatment responders [75].

A randomized clinical trial is currently ongoing to confirm the efficacy and safety of combined IVIg and corticosteroid (intravenous methylprednisolone) induction treatment, to compare this combined therapy with IVIg treatment alone [76].

\section{Plasma Exchange and Immunoadsorption}

Therapeutic plasma exchange (PLEx) may provide an alternative therapy for patients who do not respond to IVIg and corticosteroids; it can be very effective, especially in patients who have a relapsing disease course or with severe relapses [77, 78]. A PLEx course of 5-10 every-other-day sessions within 2-4 weeks is commonly used [9]. Several small trials have shown that between 48 and $81 \%$ of CIDP patients have significant short-term improvement after PLEx, but rapid deterioration may occur after completion of treatment $[77,79]$.

Recently, a small prospective randomized trial compared the use of immunoadsorption (IA) or PLEx in 20 CIDP patients, and the authors reported a similar rate of clinical improvement and side effects between the 2 treatments [80]. Another randomized study compared IA with IVIg in CIDP, and response rates to IA were not significantly different [81]. PLEx therapy removes a broad range of circulating molecules and requires the use of replacement fluid. In contrast, replacement fluid is not required in IA, and the range of circulating factors removed is more limited [82]. Moreover, there are variations in the biological effects between the different types of IA, which may also influence their clinical efficacy. Davies et al. reviewed the use of IA and PLEx in a cohort of 41 patients with nodal/paranodal antibodies. Twenty of them were treated with PLEx and 4 with IA, but none of these patients had a good response to either of these treatments. Moreover, they observed that GBS/CIDP patients without detectable $\mathrm{IgG}$ antibodies on routine diagnostic tests had a better response to apheresis, particularly IA. They also described a patient with anti-NF155 antibodies treated with IA, in which the therapy was able to reduce antibody titres, but levels quickly rebounded and reached pre-treatment levels. Based on this observation, it can be inferred that more prolonged suppression of antibody titres with frequent apheresis cycles may therefore be required for effective treatment in such cases [82].

\section{Rituximab}

Rituximab is an antibody that targets CD20 on B cells, resulting in $\mathrm{B}$ cell depletion. It has been reported to be effective in patients not responding to conventional treatment, particularly in autoimmune nodopathy patients [64]. Some authors, including ourselves, have observed reductions in IgG4 autoantibody levels in CIDP patients treated with rituximab (personal observation).

It has been proposed that the combination of rituximab with IA may offer significant benefit over rituximab alone, but this observation requires further investigation [82].

Currently, two Italian and one Japanese randomized clinical trials are ongoing to determine the efficacy and safety of rituximab in patients with CIDP responsive to IVIg and in patients with refractory CIDP with or without nodal antibodies $[60,83]$.

\section{Other Treatment Strategies and Emerging Therapies}

Further treatment options for CIDP patients include immunosuppresants or autologous stem cell transplantation [84]. Randomized studies analyzing the efficacy of azathioprine, interferon $\beta$-1a, and methrotexate have shown no significant treatment effect [55]. The recent randomized clinical trial comparing fingolimod with placebo was also prematurely stopped due to lack of efficacy [85]. Some case reports or small studies have reported effectiveness of cyclophosphamide, etanercept, eculizumab alemtuzumab, and others, but larger randomized controlled trials are required to confirm efficacy [9].

Several ongoing trials are addressing novel therapeutic approaches in CIDP. Under the hypothesis that CIDP is mainly an autoantibody-mediated disorder and its good response to IVIg, inhibition of the neonatal receptor of $\mathrm{Fc}$ portion of immunoglobulins ( $\mathrm{FcRN}$ ) has been suggested as a potential therapy in CIDP. These therapies, that have already shown efficacy in other autoantibody-mediated disorders, exert their mechanism of action by increasing IgG catabolism and rapidly removing pathogenic autoantibodies from circulation. Several compounds addressing this mechanism are currently being evaluated, but no data on their efficacy is available yet. Complement activation has also been reported in CIDP patients [17, 43, 86]. Whether this activation is a pathophysiological mechanism in CIDP that appears regardless of the presence of autoantibodies is unknown. In any case, complement inhibition, a therapeutic strategy that has been successful in other autoantibody-mediated disorders 
[87], is also a potential future therapeutic strategy in CIDP that is also currently under investigation.

\section{Guillain-Barré Syndrome}

Guillain-Barré Syndrome (GBS) is an acute inflammatory neuropathy with an heterogeneous presentation and pathogenesis [88]. The incidence ranges from 0.9 to 1.9 cases per 100,000 people per year, with male predominance and increasing incidence with age. Diagnosis is mainly clinical, and electrophysiological tests and CSF are used as supportive criteria; specific diagnostic biomarkers are not available for most variants of the syndrome $[89,90]$.

GBS is considered a paradigmatic post-infectious autoimmune disorder of the peripheral nerves and nerve roots, characterized by leukocyte infiltration of the nerves that leads to demyelination and axonal loss [91]. In most patients, the acute onset of neurological symptoms is preceded by an infectious triggering event, followed by progressive limb weakness and arreflexia, which can progress for 4 weeks before reaching clinical stability [90]. Several clinical and electrophysiological forms with different prognoses have been described within the GBS syndrome. The most common subtypes of GBS are acute demyelinating inflammatory polyneuropathy (AIDP) and acute motor axonal neuropathy (AMAN) [92]. Other clinical syndromes, such as Miller Fisher syndrome, although different in their clinical presentation, are pathophysiologically considered within the GBS spectrum.

Diverse mechanisms, including humoral and cellular immune responses, autoantibodies and complement, and activated macrophages and lymphocytes, have been implicated in GBS pathogenesis. However, the exact role and temporal sequence in which these immunopathogenic mechanisms appear remain relatively unknown [4].

\section{Immunopathogenesis}

The immunopathogenesis of GBS is only partially known, based on limited pathological data that mostly dates back to decades ago and on the acute experimental neuritis (EAN) model. The seminal pathological studies by Haymaker and Kernohan describe that the first pathological event in GBS is the appearance of endoneurial edema in spinal nerves, particularly where the ventral and dorsal rami join to form peripheral nerves. This edema of the ventral rami of the spinal nerves has been proposed to associate with early inexcitability of motor nerves due to proximal nerve ischemia in fulminant GBS cases [93]. After this initial phase, from day 9 onwards, inflammatory infiltrates, including macrophages, appear [94]. These observations suggest that humoral effector mechanisms are the ones driving disease onset, followed by cellular effector mechanisms that contribute to nerve damage and repair. Other authors suggest that macrophagemediated segmental demyelination with a lymphoplasmocytic infiltrate is the hallmark of GBS pathology, but these discrepancies probably relate to nerve specimen obtention timing [95].

Approximately two-thirds of patients with GBS disease starts with an antecedent infectious event happening up to 4 weeks before the onset of the disease. Six major pathogens have been associated with GBS in case-control studies: Campylobacter jejuni, cytomegalovirus, hepatitis E virus, Mycoplasma pneumoniae, Epstein-Barr virus and Zika virus [92, 96-98]. Recently, emerging reports of GBS in association with SARS-Cov-2 infection have been published, although a causal relationship has not been demonstrated [99]. This direct relationship with a previous infection supported the role of molecular mimicry between antigens of the infectious agent and the peripheral nerve as the driver of autoimmunity in GBS $[4,100]$. According to this model, the immune response targeting an infection leads to the appearance of antibodies that cross-react with peripheral nerve and nerve root gangliosides, triggering post-infectious inflammation that results in nerve damage or functional nerve conduction blocks [101, 102].

The molecular mimicry hypothesis has been demonstrated for Campylobacter jejuni and the motor variants of GBS. In this case, antibodies targeting the lipooligosaccharide of the $C$. jejuni bacterial wall cross reacts with the GM1 ganglioside of the peripheral nerves [103]. Then, deposition of anti-GM1 autoantibodies at the nodal axolemma of motor fibers results in the activation of the complement cascade, leading to axonal damage [104]. Deposition of complement has also been demonstrated in the AIDP variants of GBS [105]. Despite no clear autoantibody associations have been found in this GBS subset, it is postulated that binding of unknown autoantibodies targeting Schwann cell epitopes could determine complement activation and lead to the appearance of inflammation and demyelination.

The pathological injury in AIDP takes place at the myelin sheath. Electron microscopy studies of sural nerve biopsies of patients with AIDP demonstrated the presence of T cells and macrophage infiltrates that trigger macrophage-induced demyelination, which was morphologically indistinguishable from the demyelination observed in CIDP [106]. In contrast, in AMAN patients, the axolemma is the primary target for immune-related injury, and histological studies of AMAN nerves showed axonal injury without $\mathrm{T}$ cell inflammation or demyelination [104]. In the early stage of AMAN, there is an immune attack to the node of Ranvier with destruction of sodium-voltage (Nav) channel clusters and nerve conduction failure; if the attack progresses, calcium enters into the axons, and protease activation induces axonal damage and degeneration [28, 107]. 
The findings in AIDP and AMAN pathology complement the initial descriptions from Haymaker and Kernohan, because antibody deposition and complement activation may be the drivers of the initial edema, and then followed by T cell and macrophage infiltration, but significant knowledge gaps remain to be elucidated. The improvement in GBS outcomes and the scarcity of biopsy and necropsy samples make immunopathological studies more difficult; future studies should try to address the injury sites and molecular features of GBS immunopathology or find surrogate markers (imaging, neurophysiological, or soluble biomarkers) that help elucidate GBS immunopathology [108-110].

\section{Anti-Ganglioside Antibodies}

Gangliosides are sialic acid-containing glycosphingolipids present in neuronal membranes, including those of peripheral nerves, but are also minor constituents of myelin [111, 112].

Anti-ganglioside antibodies are the most commonly recognized autoimmune marker in all GBS variants: they can be found in about half of all patients in the acute phase of GBS [113]. Anti-GM1 and anti-GQ1b, associating with AMAN [114] and Miller Fisher variants [115], are the most clinically relevant antibodies in GBS, but many other gangliosides have also been identified as antibody targets [111]. As previously described, these autoantibodies arise via microbial molecular mimicry [116].

Some studies have demonstrated the pathogenic role of anti-ganglioside antibodies, especially anti-GM1 antibodies. Anti-GM1 antibodies can activate complement and disrupt the function of the node of Ranvier in the motor axons [117]. In mutant mice lacking anti-GM1 and anti-GD1a antibodies, the paranodal loops fail to attach to the axolemma with widening of the node [28]. Moreover, in a rabbit model immunized with GM1, anti-GM1 antibodies bound to the nodes of Ranvier and activated complement, resulting in the destruction of Nav channels, paranodal detachment of myelin loops, and widening of the nodes [118, 119]. Another study demonstrated that anti-GD1a and/or GM1 antibodies from GBS patients inhibit axonal regeneration in dorsal root ganglion (DRG) neurons and impair functional recovery in anti-ganglioside-treated animals after sciatic nerve injury, suggesting that anti-ganglioside antibodies mediate nerve repair inhibition [120].

\section{Other Autoantibodies}

While AMAN and Miller Fisher GBS variants are associated with specific anti-ganglioside antibodies, the precise targets for immune attack in AIDP, the most common GBS variant, remain unknown.
As found in CIDP, a subset of patients fulfilling GBS diagnostic criteria also associate with antibodies against nodal and paranodal proteins (neurofascin 140/186 [44, 53], neurofascin 155 [34], CASPR1 [46, 121], and contactin 1 [121]). Most of them are aggressive presentations of autoimmune nodopathies that respond poorly to conventional GBS therapies; a few remain monophasic and respond to intravenous immunoglobulins.

Other autoantibodies targeting myelin proteins, heat shock proteins, moesin, tubulin, and other nerve antigens have also been described, but their immunological and clinical relevance has not been elucidated [122-124]. Vallat et al. detected that a significant percentage of GBS patients (about $25 \%$ ) presented with IgG or IgM reactivity against myelin, and that the staining patterns on Schwann cells were diverse, suggesting that a variety of myelin antigens, yet to be discovered, are being recognized by autoantibodies [125].

\section{Treatments}

Effective therapies in GBS are limited to PLEx [126] and IVIg [127] since 30 years ago. Both treatments have been shown to be equally effective in improving disease outcomes, but their effect is limited, and, often, disease keeps worsening, and permanent nerve damage appears despite early treatment [128]. Treatment algorithms propose that immunomodulatory therapy should be started in patients that are unable to walk independently for $10 \mathrm{~m}$; nevertheless, although evidence on treatment efficacy in patients who can still walk independently is limited, treatment should be considered if those patients continue to deteriorate or present with disabling symptoms other than ambulation loss [92].

Although most patients improve significantly, prognosis can remain poor with severe disability or death in $9-17 \%$ of all GBS patients, and significant proportions of patients show long-term fatigue or pain [92].

\section{Plasma Exchange}

PLEx exerts its beneficial effect by removing circulating antibodies, immune complexes, complement factors, cytokines, and other pro-inflammatory humoral mediators that contribute to GBS immunopathogenesis [129]. PLEx was the first therapy to formally demonstrate efficacy in GBS when administered within the first 4 weeks from onset; however, treatment should be initiated as soon as possible, ideally within the first 2 weeks to avoid permanent nerve damage [3]. The most frequent plasma exchange regimen consists of 5 courses over 2 weeks, involving a total of about five plasma volumes [113].

PLEx speeds up recovery from GBS, but it is associated with adverse effects and logistic burden. For that reason, the 
general use of this treatment in GBS has been limited since the appearance of IVIg [130].

Immunoadsorption, as an alternative to plasma exchange, is occasionally used as a treatment for GBS patients and may be equally effective. However, it has not been tested in any randomized controlled trial [113]. In resource-scarce settings, small-volume plasma exchange has also been assessed as a cost-effective potential therapy in GBS exploiting the same treatment mechanisms than PLEx [131].

\section{IVlg}

The first randomized clinical trial assessing IVIg efficacy in GBS was published in 1992 and demonstrated that IVIg was as effective as PLEx [132]. However, combination of PLEx and IVIg was not significantly better than PLEx or IVIg alone [133, 134].

The standard treatment for GBS is one course of IVIg of $2 \mathrm{~g} / \mathrm{kg}$ over 5 days. Despite treatment, approximately $20 \%$ of patients are unable to walk independently at 6 months [113]. Interestingly, it has been found that a larger increase in serum IgG levels 2 weeks after the first IVIg course is associated with a better outcome [135]. Considering these observations, the IGOS Consortium has reported the observational I-SID study, in which GBS patients with a poor prognosis who were treated with one IVIg course were compared with patients treated with two IVIg courses. Although the use of a second course of IVIg treatment is a common practice (around 25\% of patients are given a second IVIg dose) [136], the authors did not reported better outcomes after a second IVIg course in GBS with poor prognosis [137]. Moreover, the recently published SID-GBS study, a randomized, double-blind, placebo-controlled trial, did not provide evidence that GBS patients with a poor prognosis benefit from a second IVIg course and showed that patients given a second IVIg course had more serious adverse effects. Second IVIg courses should not be administered in GBS patients with poor prognosis [138].

\section{Complement Inhibitors}

Complement deposition and activation have been described both in GBS patients and in GBS models [139]. In a mouse model of GBS, pathological and electrophysiological alterations were prevented by eculizumab, a humanized monoclonal antibody that specifically binds to complement $\mathrm{C} 5$ and inhibits the development of the membrane attack complex [140]. The crucial role of complement demonstrated in animal models prompted two randomized controlled trials to find out whether eculizumab, added to IVIg, is beneficial in GBS [141, 142]. In one of the trials, that did not met its primary endpoint on efficacy, GBS patients who received eculizumab in addition to a course of IVIg were more likely to run at 6 months of disease onset, suggesting a better, faster recovery than patients who received only a course of IVIg. Novel trials exploring complement inhibition in GBS are currently underway (Clinicaltrials. gov identifier: NCT04701164).

\section{Other Treatment Strategies}

In contrast with CIDP, other immunotherapies such as corticosteroids are not effective according to clinical trials and observational studies and should not be used in these patients [143].

In an AMAN rabbit model, IdeS (a Streptococcus pyogenes-derived protease) reduced the frequency of axonal motor degeneration and improved recovery [144, 145]. Streptococcus pyogenes-derived proteases exert their beneficial effect by depleting most peripheral $\operatorname{IgG}$ (and, thus, pathogenic autoantibodies). The efficacy of this therapeutic strategy in GBS patients is currently being investigated in a phase 2 clinical trial with imlifidase [146].

In a murine GBS model, recombinant antibodies that inhibit $\mathrm{FcRn}$ (neonatal $\mathrm{Fc}$ receptor that is pivotal in IgG homeostasis) enhanced degradation of circulating anti-ganglioside antibodies, preventing antibody-mediated neuronal injury [147]; however, to date, clinical trials exploiting the FcRN inhibition strategy in GBS are not planned yet.

Another recent study showed that blocking of TLR4 signaling with TAK 242 protected L31 mice (a transgenic mouse that spontaneously develop autoimmune peripheral neuropathy between 4 and 6 months) from severe myelin and axonal loss, resulting in an improvement in mouse motor and sensory functions [91]. Interestingly, previous studies reported increased expression of TLR4 in GBS patients [148]. Moreover, TLR4 299Gly polymorphisms were associated with an increased susceptibility to GBS $[149,150]$. All this observations provide evidence to support TLR4 as a useful drug target for treating GBS, but trials using this therapeutic strategy are not yet planned.

\section{Conclusion}

CIDP and GBS are clinically and immunopathologically heterogeneous disorders in which very few effective (and unspecific) immunomodulatory therapies are available. Biomarkers informing disease classification and, most importantly, treatment selection and monitoring are lacking. These features result in misdiagnosis, overtreatment, treatment failure, and suboptimal outcomes, and thus, research on disease pathophysiology aiming to reveal clinically and functionally relevant disease mechanisms is needed to optimize the diagnostic and therapeutic outcomes in GBS and CIDP. The classification of patients according to autoantibody profiles and the recent description of nerve damage biomarkers represent 
potential strategies to address these challenges. However, the low incidence of these disorders requires that multicentric and multiparametric studies such as the International CIDP database (www.INCBase.org) [151] and the International GBS Outcome Study [152] help in understanding the mechanisms underlying these diseases that could serve as therapeutic targets.

Supplementary Information The online version contains supplementary material available at https://doi.org/10.1007/s13311-021-01117-3.

Required Author Forms Disclosure forms provided by the authors are available with the online version of this article.

\section{References}

1. B. C. Kieseier, E. K. Mathey, C. Sommer, and H. P. Hartung, "Immune-mediated neuropathies," Nat. Rev. Dis. Prim., vol. 4, no. 1, 2018, https://doi.org/10.1038/s41572-018-0027-2.

2. D. Schafflick, B. C. Kieseier, H. Wiendl, and G. Meyer zu Horste, "Novel pathomechanisms in inflammatory neuropathies," J. Neuroinflammation, vol. 14, no. 1, pp. 1-17, 2017, https://doi.org/10. 1186/s12974-017-1001-8.

3. J. M. Léger, R. Guimarães-Costa, and C. Muntean, "Immunotherapy in Peripheral Neuropathies," Neurotherapeutics, vol. 13, no. 1, pp. 96-107, 2016, https://doi.org/10.1007/s13311-015-0401-7.

4. L. Martín-Aguilar, E. Pascual-Goñi, and L. Querol, "Autoantibodies in immune-mediated inflammatory neuropathies," Med. Clínica (English Ed., vol. 153, no. 9, pp. 360-367, 2019, https:// doi.org/10.1016/j.medcle.2019.06.015.

5. M. C. Broers, C. Bunschoten, D. Nieboer, H. F. Lingsma, and B. C. Jacobs, "Incidence and Prevalence of Chronic Inflammatory Demyelinating Polyradiculoneuropathy: A Systematic Review and Meta-Analysis," Neuroepidemiology, pp. 161-172, 2019, https://doi.org/10.1159/000494291.

6. E. K. Mathey et al., "Chronic inflammatory demyelinating polyradiculoneuropathy: From pathology to phenotype," J. Neurol. Neurosurg. Psychiatry, vol. 86, no. 9, pp. 973-985, 2015, https:// doi.org/10.1136/jnnp-2014-309697.

7. P. E. Doneddu et al., "Atypical CIDP: Diagnostic criteria, progression and treatment response. Data from the Italian CIDP Database," J. Neurol. Neurosurg. Psychiatry, vol. 90, no. 2, pp. 125-132, 2019, https://doi.org/10.1136/jnnp-2018-318714.

8. P. Y. K. Van den Bergh et al., "European Academy of Neurology/ Peripheral Nerve Society guideline on diagnosis and treatment of chronic inflammatory demyelinating polyradiculoneuropathy: Report of a joint Task Force-Second revision," Eur. J. Neurol., no. May, pp. 1-28, 2021, https://doi.org/10.1111/ene.14959.

9. C. Bunschoten, B. C. Jacobs, P. Y. K. Van den Bergh, D. R. Cornblath, and P. A. van Doorn, "Progress in diagnosis and treatment of chronic inflammatory demyelinating polyradiculoneuropathy," Lancet Neurol., vol. 18, no. 8, pp. 784-794, 2019, https://doi.org/10.1016/S1474-4422(19)30144-9.

10. Hagen, K.M., Ousman, S.S. The immune response and aging in chronic inflammatory demyelinating polyradiculoneuropathy. J Neuroinflammation 18, 78 (2021). https://doi.org/10.1186/ s12974-021-02113-2

11. S. Ikeda et al., "Clinicopathological characteristics of subtypes of chronic inflammatory demyelinating polyradiculoneuropathy," J. Neurol. Neurosurg. Psychiatry, vol. 90, no. 9, pp. 988-996, 2019, https://doi.org/10.1136/jnnp-2019-320741.
12. J. M. Spies, K. W. Westland, J. G. Bonner, and J. D. Pollard, "Intraneural activated $t$ cells cause focal breakdown of the blood-nerve barrier," Brain, vol. 118, no. 4, pp. 857-868, 1995, https://doi.org/10.1093/brain/118.4.857.

13. J. D. Pollard et al., "Activated T cells of nonneural specificity open the blood-nerve barrier to circulating antibody," Ann. Neurol., vol. 37, no. 4, pp. 467-475, 1995, https://doi.org/10. 1002/ana.410370409.

14. H. Koike and M. Katsuno, "Pathophysiology of Chronic Inflammatory Demyelinating Polyneuropathy: Insights into Classification and Therapeutic Strategy," Neurol. Ther., vol. 9, no. 2, pp. 213-227, 2020, https://doi.org/10.1007/ s40120-020-00190-8.

15. B. Schmidt, K. V. Toyka, R. Kiefer, J. Full, H. P. Hartung, and J. Pollard, "Inflammatory infiltrates in sural nerve biopsies in Guillain-Barré syndrome and chronic inflammatory demyelinating neuropathy," Muscle and Nerve, vol. 19, no. 4, pp. 474-487, 1996. https://doi.org/10.1002/(SICI)1097-4598(199604)19:4< 474::AID-MUS8>3.0.CO;2-9

16. C. Sommer, S. Koch, M. Lammens, A. Gabreels-Festen, G. Stoll, and K. V. Toyka, "Macrophage clustering as a diagnostic marker in sural nerve biopsies of patients with CIDP," Neurology, vol. 65 , no. 12 , pp. 1924-1929, 2005, https://doi.org/10.1212/01.wnl. 0000188879.19900.b7.

17. H. Koike et al., "Complement deposition and macrophageinduced demyelination in CIDP with anti-LM1 antibodies," $J$. Neurol. Sci., vol. 408, no. October 2019, pp. 2019-2021, 2020, https://doi.org/10.1016/j.jns.2019.116509.

18. R. Kiefer, B. C. Kieseier, G. Stoll, and H. P. Hartung, "The role of macrophages in immune-mediated damage to the peripheral nervous system," Prog. Neurobiol., vol. 64, no. 2, pp. 109-127, 2001, https://doi.org/10.1016/S0301-0082(00)00060-5.

19. L. J. Chi, W. H. Xu, Z. W. Zhang, H. T. Huang, L. M. Zhang, and J. Zhou, "Distribution of Th17 cells and Th1 cells in peripheral blood and cerebrospinal fluid in chronic inflammatory demyelinating polyradiculoneuropathy," J. Peripher. Nerv. Syst., vol. 15, no. 4, pp. 345-356, 2010, https://doi.org/10.1111/j.1529-8027.2010.00294.x.

20. [20]V. Brucklacher-Waldert, K. Stuerner, M. Kolster, J. Wolthausen, and E. Tolosa, "Phenotypical and functional characterization of T helper 17 cells in multiple sclerosis," Brain, vol. 132, no. 12, pp. 3329-3341, 2009, https://doi.org/10.1093/brain/ awp289.

21. A. Henriques et al., "Frequency and functional activity of Th17, Tc17 and other T-cell subsets in Systemic Lupus Erythematosus," Cell. Immunol., vol. 264, no. 1, pp. 97-103, 2010, https:// doi.org/10.1016/j.cellimm.2010.05.004.

22. M. Heming et al., "Immune cell profiling of the cerebrospinal fluid provides pathogenetic insights into inflammatory neuropathies," Front. Immunol., vol. 10, no. MAR, pp. 1-11, 2019, https://doi.org/10.3389/fimmu.2019.00515.

23. A. K. Mausberg et al., "Recovery of the T-cell repertoire in CIDP by IV immunoglobulins," Neurology, vol. 80, no. 3, pp. 296-303, 2013, https://doi.org/10.1212/WNL.0b013e31827debad.

24. B. Tackenberg et al., "Impaired inhibitory Fcy receptor IIB expression on B cells in chronic inflammatory demyelinating polyneuropathy," Proc. Natl. Acad. Sci. U. S. A., vol. 106, no. 12, pp. 4788-4792, 2009, https://doi.org/10.1073/pnas.0807319106.

25. I. Quast, F. Cueni, F. Nimmerjahn, B. Tackenberg, and J. D. Lunemann, "Deregulated Fcy receptor expression in patients with CIDP," Neurol. Neuroimmunol. NeuroInflammation, vol. 2, no. 5, p. e148, 2015, https://doi.org/10.1212/NXI.0000000000000148.

26. C. Ritter, D. Förster, P. Albrecht, H. P. Hartung, B. C. Kieseier, and H. C. Lehmann, "IVIG regulates BAFF expression in patients with chronic inflammatory demyelinating polyneuropathy (CIDP)," $J$. Neuroimmunol., vol. 274, no. 1-2, pp. 225-229, 2014, https://doi. org/10.1016/j.jneuroim.2014.06.007. 
27. L. Querol, J. Devaux, R. Rojas-Garcia, and I. Illa, "Autoantibodies in chronic inflammatory neuropathies: Diagnostic and therapeutic implications," Nat. Rev. Neurol., vol. 13, no. 9, pp. 533-547, 2017, https://doi.org/10.1038/nrneurol.2017.84.

28. A. Uncini and J. M. Vallat, "Autoimmune nodo-paranodopathies of peripheral nerve: The concept is gaining ground," J. Neurol. Neurosurg. Psychiatry, vol. 89, no. 6, pp. 627-635, 2018, https:// doi.org/10.1136/jnnp-2017-317192.

29. M. G. Huijbers et al., "The expanding field of IgG4-mediated neurological autoimmune disorders," Eur. J. Neurol., vol. 22, no. 8, pp. 1151-1161, 2015, https://doi.org/10.1111/ene.12758.

30. E. Burnor et al., "Neurofascin antibodies in autoimmune, genetic, and idiopathic neuropathies," Neurology, vol. 90, no. 1, pp. E31E38, 2018, https://doi.org/10.1212/WNL.0000000000004773.

31. K. Doppler et al., "Neurofascin-155 IgM autoantibodies in patients with inflammatory neuropathies," J. Neurol. Neurosurg. Psychiatry, pp. 1145-1151, 2018, https://doi.org/10.1136/jnnp-2018-318170.

32. A. Fujita, H. Ogata, R. Yamasaki, T. Matsushita, and J. ichi Kira, "Parallel fluctuation of anti-neurofascin 155 antibody levels with clinico-electrophysiological findings in patients with chronic inflammatory demyelinating polyradiculoneuropathy," J. Neurol. Sci., vol. 384, no. November 2017, pp. 107-112, 2018, https:// doi.org/10.1016/j.jns.2017.11.035.

33. C. Manso et al., "Anti - neurofascin-155 IgG4 antibodies prevent paranodal complex formation in vivo Find the latest version : Anti - neurofascin-155 IgG4 antibodies prevent paranodal complex formation in vivo," vol. 129, no. 6, pp. 2222-2236, 2019.

34. Ng JK, Malotka J, Kawakami N, Derfuss T, Khademi M, Olsson T, Linington C, Odaka M, Tackenberg B, Prüss H, Schwab JM, Harms L, Harms H, Sommer C, Rasband MN, Eshed-Eisenbach Y, Peles E, Hohlfeld R, Yuki N, Dornmair K, Meinl E. Neurofascin as a target for autoantibodies in peripheral neuropathies. Neurology. 2012 Dec 4;79(23):2241-8. https://doi.org/10.1212/ WNL.0b013e31827689ad. Epub 2012 Oct 24. PMID: 23100406; PMCID: PMC3542349.

35. Z. Wang, X. Zhou, N. Zhao, C. Xie, D. Zhu, and Y. Guan, "Neurofascin antibodies in chronic inflammatory demyelinating polyradiculoneuropathy: from intrinsic genetic background to clinical manifestations," Neurol. Sci., vol. 42, no. 6, pp. 2223-2233, 2021, https://doi.org/10.1007/s10072-021-05220-3.

36. H. Koike et al., "Paranodal dissection in chronic inflammatory demyelinating polyneuropathy with anti-neurofascin-155 and anti-contactin-1 antibodies," J. Neurol. Neurosurg. Psychiatry, vol. 88, no. 6, pp. 465-473, 2017, https://doi.org/10.1136/ jnnp-2016-314895.

37. L. Martinez-Martinez et al., "Anti-NF155 chronic inflammatory demyelinating polyradiculoneuropathy strongly associates to HLA-DRB15," J. Neuroinflammation, 2017, https://doi.org/10. 1186/s12974-017-0996-1.

38. L. Querol et al., "Antibodies to contactin-1 in chronic inflammatory demyelinating polyneuropathy," Ann. Neurol., vol. 73, no. 3, pp. 370-380, 2013, https://doi.org/10.1002/ana.23794.

39. E. Delmont et al., "Antibodies against the node of Ranvier: a real-life evaluation of incidence, clinical features and response to treatment based on a prospective analysis of 1500 sera," $J$. Neurol., vol. 267, no. 12, pp. 3664-3672, 2020, https://doi.org/ 10.1007/s00415-020-10041-z.

40. M. Labasque, B. Hivert, G. Nogales-Gadea, L. Querol, I. Illa, and C. Faivre-Sarrailh, "Specific contactin N-glycans are implicated in neurofascin binding and autoimmune targeting in peripheral neuropathies," J. Biol. Chem., 2014, https://doi.org/10.1074/jbc.M113.528489.

41. C. Manso, L. Querol, M. Mekaouche, I. Illa, and J. J. Devaux, "Contactin-1 IgG4 antibodies cause paranode dismantling and conduction defects," Brain, 2016, https://doi.org/10.1093/brain/ aww062.
42. L. Appeltshauser, A. Weishaupt, C. Sommer, and K. Doppler, "Complement deposition induced by binding of anti-contactin-1 auto-antibodies is modified by immunoglobulins," Exp. Neurol., vol. 287, pp. 84-90, 2017, https://doi.org/10.1016/j.expneurol. 2016.10.006.

43. J. M. Vallat et al., "Subacute nodopathy with conduction blocks and anti-neurofascin 140/186 antibodies: An ultrastructural study," Brain, vol. 141, no. 7, p. e56, 2018, https://doi.org/10. 1093/brain/awy134.

44. E. Delmont et al., "Autoantibodies to nodal isoforms of neurofascin in chronic inflammatory demyelinating polyneuropathy," Brain, vol. 140, no. 7, pp. 1851-1858, 2017, https://doi.org/10. 1093/brain/awx 124.

45. H. Stengel et al., "Anti-pan-neurofascin IgG3 as a marker of fulminant autoimmune neuropathy," Neurol. Neuroimmunol. NeuroInflammation, vol. 6, no. 5, pp. 1-11, 2019, https://doi.org/10. 1212/NXI.0000000000000603.

46. K. Doppler et al., "Auto-antibodies to contactin-associated protein 1 (Caspr) in two patients with painful inflammatory neuropathy," Brain, vol. 139, no. 10, pp. 2617-2630, 2016, https://doi. org/10.1093/brain/aww189.

47. A. Cortese et al., "Antibodies to neurofascin, contactin-1, and contactin-associated protein 1 in CIDP: Clinical relevance of IgG isotype," Neurol. Neuroimmunol. neuroinflammation, vol. 7, no. 1, 2020, https://doi.org/10.1212/NXI.0000000000000639.

48. L. Appeltshauser et al., "Antiparanodal antibodies and IgG subclasses in acute autoimmune neuropathy," Neurol. Neuroimmunol. neuroinflammation, vol. 7, no. 5, pp. 1-11, 2020, https://doi. org/10.1212/NXI.0000000000000817.

49. E. Pascual-Goñi and L. Querol, "Antibodies to the Caspr1/contactin1 complex in chronic inflammatory demyelinating polyneuropathy," Brain, 2021, https://doi.org/10.1093/brain/awab014.

50. L. Sanvito et al., "Humoral and cellular immune responses to myelin protein peptides in chronic inflammatory demyelinating polyradiculoneuropathy," J. Neurol. Neurosurg. Psychiatry, vol. 80, no. 3, pp. 333-338, 2009, https://doi.org/10.1136/jnnp.2008.159798.

51. L. Querol et al., "Antibodies against peripheral nerve antigens in chronic inflammatory demyelinating polyradiculoneuropathy," Sci. Rep., vol. 7, no. 1, pp. 1-9, 2017, https://doi.org/10.1038/s41598-017-14853-4.

52. M. Kuwahara, H. Suzuki, M. Samukawa, Y. Hamada, K. Takada, and S. Kusunoki, "Clinical features of CIDP with LM1-associated antibodies," J. Neurol. Neurosurg. Psychiatry, vol. 84, no. 5, pp. 573-575, 2013, https://doi.org/10.1136/jnnp-2012-303440.

53. J. J. Devaux, M. Odaka, and N. Yuki, "Nodal proteins are target antigens in Guillain-Barré syndrome," J. Peripher. Nerv. Syst., vol. 17, no. 1, pp. 62-71, 2012, https://doi.org/10.1111/j.1529-8027.2012.00372.x.

54. K. Doppler, C. Werner, and C. Sommer, "Disruption of nodal architecture in skin biopsies of patients with demyelinating neuropathies," J. Peripher. Nerv. Syst., vol. 18, no. 2, pp. 168-176, 2013, https://doi.org/10.1111/jns5.12023.

55. A. L. Fisse, J. Motte, T. Grüter, M. Sgodzai, K. Pitarokoili, and R. Gold, "Comprehensive approaches for diagnosis, monitoring and treatment of chronic inflammatory demyelinating polyneuropathy," Neurol. Res. Pract., vol. 2, no. 1, 2020, https://doi.org/ 10.1186/s42466-020-00088-8.

56. A. R. Joshi et al., "Loss of Schwann cell plasticity in chronic inflammatory demyelinating polyneuropathy (CIDP)," J. Neuroinflammation, vol. 13, no. 1, pp. 1-9, 2016, https://doi.org/ 10.1186/s12974-016-0711-7.

57. P. J. Dyck et al., "Prednisone improves chronic inflammatory demyelinating polyradiculoneuropathy more than no treatment," Ann. Neurol., vol. 11, no. 2, pp. 136-141, 1982, https:// doi.org/10.1002/ana.410110205.

58. R. A. C. Hughes et al., "Intravenous immune globulin (10\% caprylate-chromatography purified) for the treatment of chronic inflammatory demyelinating polyradiculoneuropathy 
(ICE study): a randomised placebo-controlled trial," Lancet Neurol., vol. 7, no. 2, pp. 136-144, 2008, https://doi.org/10. 1016/S1474-4422(07)70329-0.

59. A. F. Hahn et al., "Plasma-exchange therapy in chronic inflammatory demyelinating polyneuropathy," pp. 1055-1066, 1996.

60. C. Briani, D. Cocito, M. Campagnolo, P. E. Doneddu, and E. Nobile-Orazio, "Update on therapy of chronic immune-mediated neuropathies," vol. 40, no. 8, pp. 1084-1089, 2021, [Online]. Available: http://link.springer.com/10.1007/s00059-015-4334-z.

61. A. Shahram, A. Verschueren, F. Jérome, E. Salort-Campana, E. Jouve, and J. Pouget, "Response to treatment in patients with Lewis-Sumner syndrome," Muscle and Nerve, vol. 44, no. 2, pp. 179-184, 2011, https://doi.org/10.1002/mus.22024.

62. A. Verschueren, J. P. Azulay, S. Attarian, J. Boucraut, J. F. Pellissier, and J. Pouget, "Lewis-Sumner syndrome and multifocal motor neuropathy," Muscle and Nerve, vol. 31, no. 1, pp. 88-94, 2005, https:// doi.org/10.1002/mus.20236.

63. K. Viala et al., "Follow-up study and response to treatment in 23 patients with Lewis-Sumner syndrome," Brain, vol. 127, no. 9, pp. 2010-2017, 2004, https://doi.org/10.1093/brain/awh222.

64. L. Querol et al., "Rituximab in treatment-resistant CIDP with antibodies against paranodal proteins," Neurol. Neuroimmunol. NeuroInflammation, vol. 2, no. 5, p. e149, 2015, https://doi.org/ 10.1212/NXI.0000000000000149.

65. G. G. A. van Lieverloo et al., "Serum neurofilament light chain in chronic inflammatory demyelinating polyneuropathy," $J$. Peripher. Nerv. Syst., vol. 24, no. 2, pp. 187-194, 2019, https:// doi.org/10.1111/jns.12319.

66. O. Mielke et al., "Restabilization treatment after intravenous immunoglobulin withdrawal in chronic inflammatory demyelinating polyneuropathy: Results from the pre-randomization phase of the Polyneuropathy And Treatment with Hizentra study," J. Peripher. Nerv. Syst., vol. 24, no. 1, pp. 72-79, 2019, https://doi.org/10.1111/jns.12303.

67. [68]K. Kuitwaard et al., "Randomized trial of intravenous immunoglobulin maintenance treatment regimens in chronic inflammatory demyelinating polyradiculoneuropathy," Eur. J. Neurol., vol. 28, no. 1, pp. 286-296, 2021, https://doi.org/10.1111/ene.14501.

68. [69]H. C. Lehmann and H. P. Hartung, "Plasma exchange and intravenous immunoglobulins: Mechanism of action in immunemediated neuropathies," J. Neuroimmunol., vol. 231, no. 1-2, pp. 61-69, 2011, https://doi.org/10.1016/j.jneuroim.2010.09.015.

69. J. Klehmet et al., "Effective treatment with intravenous immunoglobulins reduces autoreactive T-cell response in patients with CIDP," J. Neurol. Neurosurg. Psychiatry, vol. 86, no. 6, pp. 686-691, 2015, https://doi.org/10.1136/jnnp-2014-307708.

70. A. B. Bohn et al., "The effect of IgG levels on the number of natural killer cells and their $\mathrm{Fc}$ receptors in chronic inflammatory demyelinating polyradiculoneuropathy," Eur. J. Neurol., vol. 18, no. 6, pp. 919-924, 2011, https://doi.org/10.1111/j.1468-1331.2010.03333.x.

71. J. D. Lünemann, F. Nimmerjahn, and M. C. Dalakas, "Intravenous immunoglobulin in neurology-mode of action and clinical efficacy," Nat. Rev. Neurol., vol. 11, no. 2, pp. 80-89, 2015, https://doi.org/10.1038/nrneurol.2014.253.

72. I. N. van Schaik et al., "Subcutaneous immunoglobulin for maintenance treatment in chronic inflammatory demyelinating polyneuropathy (PATH): a randomised, double-blind, placebocontrolled, phase 3 trial," Lancet Neurol., vol. 17, no. 1, pp. 35-46, 2018, https://doi.org/10.1016/S1474-4422(17)30378-2.

73. I. N. Van Schaik et al., "Long-term safety and efficacy of subcutaneous immunoglobulin IgPro20 in CIDP: PATH extension study," Neurol. Neuroimmunol. NeuroInflammation, vol. 6, no. 5, pp. 1-14, 2019, https://doi.org/10.1212/NXI.0000000000000590.

74. R. A. C. Hughes, R. Brassington, A. A. Gunn, and P. A. van Doorn, "Corticosteroids for Guillain-Barré syndrome," Cochrane
Database Syst. Rev., vol. 2016, no. 10, 2016, https://doi.org/10. 1002/14651858.CD001446.pub5.

75. G. G. A. van Lieverloo et al., "Corticosteroids in chronic inflammatory demyelinating polyneuropathy: A retrospective, multicentre study, comparing efficacy and safety of daily prednisolone, pulsed dexamethasone, and pulsed intravenous methylprednisolone," J. Neurol., vol. 265, no. 9, pp. 2052-2059, 2018, https:// doi.org/10.1007/s00415-018-8948-y.

76. S. R. M. Bus et al., "Intravenous immunoglobulin and intravenous methylprednisolone as optimal induction treatment in chronic inflammatory demyelinating polyradiculoneuropathy: protocol of an international, randomised, double-blind, placebocontrolled trial (OPTIC)," Trials, vol. 22, no. 1, pp. 1-18, 2021, https://doi.org/10.1186/s13063-021-05083-1.

77. L. Querol et al., "Systematic literature review of burden of illness in chronic inflammatory demyelinating polyneuropathy (CIDP)," J. Neurol., vol. 0, no. 0123456789, 2020, https://doi.org/10.1007/ s00415-020-09998-8.

78. H. C. Lehmann, D. Burke, and S. Kuwabara, "Chronic inflammatory demyelinating polyneuropathy: Update on diagnosis, immunopathogenesis and treatment," J. Neurol. Neurosurg. Psychiatry, vol. 90, no. 9, pp. 981-987, 2019, https://doi.org/ 10.1136/jnnp-2019-320314.

79. M. M. Mehndiratta, R. A. C. Hughes, and J. Pritchard, "Plasma exchange for chronic inflammatory demyelinating polyradiculoneuropathy," Cochrane Database Syst. Rev., vol. 2017, no. 11, 2015, https://doi.org/10.1002/14651858.CD003906.pub4.

80. I. Lieker, T. Slowinski, L. Harms, K. Hahn, and J. Klehmet, "A prospective study comparing tryptophan immunoadsorption with therapeutic plasma exchange for the treatment of chronic inflammatory demyelinating polyneuropathy*," J. Clin. Apher., vol. 32, no. 6, pp. 486-493, 2017, https://doi.org/10.1002/jca.21546.

81. J. Dorst, A. C. Ludolph, M. Senel, and H. Tumani, "Short-term and long-term effects of immunoadsorption in refractory chronic inflammatory demyelinating polyneuropathy: a prospective study in 17 patients," J. Neurol., vol. 265, no. 12, pp. 2906-2915, 2018, https://doi.org/10.1007/s00415-018-9082-6.

82. A. Davies, J. Fehmi, M. Senel, H. Tumani, J. Dorst, and S. Rinaldi, "Immunoadsorption and Plasma Exchange in Seropositive and Seronegative Immune-Mediated Neuropathies," J. Clin. Med., vol. 9, no. 7, p. 2025, 2020, https://doi.org/10.3390/jcm9072025.

83. S. Shimizu et al., "Efficacy and safety of Rituximab in refractory CIDP with or without IgG4 autoantibodies (RECIPE): Protocol for a double-blind, randomized, placebo-controlled clinical trial," JMIR Res Protoc., 2020.

84. R. K. Burt et al., "Hematopoietic stem cell transplantation for chronic inflammatory demyelinating polyradiculoneuropathy," $J$. Neurol., vol. 267, no. 11, pp. 3378-3391, 2020, https://doi.org/ 10.1007/s00415-020-10010-6.

85. R. Hughes et al., "Oral fingolimod for chronic inflammatory demyelinating polyradiculoneuropathy (FORCIDP Trial): a double-blind, multicentre, randomised controlled trial," Lancet Neurol., vol. 17, no. 8, pp. 689-698, 2018, https://doi.org/10. 1016/S1474-4422(18)30202-3.

86. I. Quast, C. W. Keller, F. Hiepe, B. Tackenberg, and J. D. Lünemann, "Terminal complement activation is increased and associated with disease severity in CIDP," Ann. Clin. Transl. Neurol., vol. 3, no. 9, pp. 730-735, 2016, https://doi.org/10.1002/acn3.331.

87. J. F. Howard et al., "Safety and efficacy of eculizumab in antiacetylcholine receptor antibody-positive refractory generalised myasthenia gravis (REGAIN): a phase 3, randomised, doubleblind, placebo-controlled, multicentre study," Lancet Neurol., vol. 16, no. 12, pp. 976-986, 2017, https://doi.org/10.1016/ S1474-4422(17)30369-1. 
88. S. Esposito and M. R. Longo, "Guillain-Barré syndrome," Autoimmun. Rev., vol. 16, no. 1, pp. 96-101, 2017, https://doi.org/10. 1016/j.autrev.2016.09.022.

89. S. Rinaldi, “" syndrome Update on Guillain-Barr e," vol. 112, pp. 99-112, 2013.

90. H. J. Willison, B. C. Jacobs, and P. A. van Doorn, "GuillainBarré syndrome.," Lancet (London, England), Feb. 2016, https:// doi.org/10.1016/S0140-6736(16)00339-1.

91. O. Oladiran, X. Q. Shi, M. Yang, S. Fournier, and J. Zhang, "Inhibition of TLR4 signaling protects mice from sensory and motor dysfunction in an animal model of autoimmune peripheral neuropathy," pp. 1-17, 2021.

92. S. E. Leonhard et al., "Diagnosis and management of GuillainBarré syndrome in ten steps," Nat. Rev. Neurol., vol. 15, no. 11, pp. 671-683, 2019, https://doi.org/10.1038/s41582-019-0250-9.

93. J. Berciano, "Axonal degeneration in Guillain-Barré syndrome: a reappraisal," J. Neurol., no. 0123456789, 2020, https://doi.org/ 10.1007/s00415-020-10034-y.

94. J. Berciano, "Spinal nerve involvement in early Guillain-Barré syndrome: The Haymaker and Kernohan's legacy," J. Neurol. Sci., vol. 382, no. September, pp. 1-9, 2017, https://doi.org/10. 1016/j.jns.2017.09.017.

95. A. K. Asbury and B. G. Arnason, "The inflammatory lesion in idiopathic polyneuritis. Its role in pathogenesis." 1969.

96. V. M. Cao-Lormeau et al., "Guillain-Barré Syndrome outbreak associated with Zika virus infection in French Polynesia: A case-control study," Lancet, vol. 387, no. 10027, pp. 1531-1539, 2016, https://doi.org/10.1016/S0140-6736(16)00562-6.

97. B. Van Den Berg et al., "Guillain-Barré syndrome associated with preceding hepatitis E virus infection," Neurology, vol. 82, no. 6, pp. 491-497, 2014, https://doi.org/10.1212/WNL.0000000000000111.

98. "The spectrum of antecedent infecions in GBS. A case-control study," https://doi.org/10.1007/978-1-4614-6486-0_11.

99. S. Keddie et al., "Epidemiological and cohort study finds no association between COVID-19 and Guillain-Barré syndrome," vol. 0, pp. 2-25.

100. P. Restrepo-Jiménez, Y. Rodríguez, P. González, C. Chang, M. E. Gershwin, and J. M. Anaya, "The immunotherapy of GuillainBarré syndrome," Expert Opin. Biol. Ther., vol. 18, no. 6, pp. 619-631, 2018, https://doi.org/10.1080/14712598.2018.1468885.

101. R. Van Koningsveld et al., "Infections and course of disease in mild forms of Guillain-Barré syndrome," Neurology, vol. 58, no. 4, pp. 610-614, 2002, https://doi.org/10.1212/WNL.58.4.610.

102. N. Yuki, "Infectious origins of, and molecular mimicry in, GuillainBarré and Fisher syndromes," Lancet Infect. Dis., vol. 1, no. 1, pp. 29-37, 2001, https://doi.org/10.1016/S1473-3099(01)00019-6.

103. N. Yuki et al., "Carbohydrate mimicry between human ganglioside GM1 and Campylobacter jejuni lipooligosaccharide causes Guillain-Barré syndrome," Proc. Natl. Acad. Sci. U. S. A., vol. 101, no. 31, pp. 11404-11409, 2004, https://doi.org/ 10.1073/pnas.0402391101.

104. C. Hafer-Macko et al., "Acute motor axonal neuropathy: An antibodymediated attack on axolemma," Ann. Neurol., vol. 40, no. 4, pp. 635-644, 1996, https://doi.org/10.1002/ana.410400414.

105. C. E. Hafer-Macko et al., "Immune attack on the Schwann cell surface in acute inflammatory demyelinating polyneuropathy," Ann. Neurol., vol. 39, no. 5, pp. 625-635, 1996, https://doi.org/ 10.1002/ana.410390512.

106. H. Koike et al., "Ultrastructural mechanisms of macrophageinduced demyelination in Guillain-Barré syndrome," J. Neurol. Neurosurg. Psychiatry, vol. 91, no. 6, pp. 650-659, 2020, https:// doi.org/10.1136/jnnp-2019-322479.

107. J. W. Griffin et al., "Early nodal changes in the acute motor axonal neuropathy pattern of the Guillain-Barré syndrome," $J$. Neurocytol., vol. 25, no. 1, pp. 33-51, 1996, https://doi.org/10. 1007/BF02284784
108. G. Capodivento et al., "CSF sphingomyelin: A new biomarker of demyelination in the diagnosis and management of CIDP and GBS," J. Neurol. Neurosurg. Psychiatry, no. November 2019, pp. 1-8, 2020, https://doi.org/10.1136/jnnp-2020-324445.

109. L. Martín-Aguilar et al., "Serum neurofilament light chain predicts long-term prognosis in Guillain-Barré syndrome patients," J. Neurol. Neurosurg. Psychiatry, pp. 1-8, 2020, https://doi.org/ 10.1136/jnnp-2020-323899.

110. J. Berciano et al., "Proximal nerve lesions in early Guillain-Barré syndrome: implications for pathogenesis and disease classification," J. Neurol., vol. 264, no. 2, pp. 221-236, 2017, https://doi. org/10.1007/s00415-016-8204-2.

111. H. J. Willison, "Anti-ganglioside antibodies in peripheral nerve pathology," Methods Mol. Biol., vol. 1804, pp. 173-188, 2018, https://doi.org/10.1007/978-1-4939-8552-4_7.

112. Y. Gong et al., "Localization of major gangliosides in the PNS: Implications for immune neuropathies," Brain, vol. 125, no. 11, pp. 2491-2506, 2002, https://doi.org/10.1093/brain/awf258.

113. B. Van Den Berg, C. Walgaard, J. Drenthen, C. Fokke, B. C. Jacobs, and P. A. Van Doorn, "Guillain-Barré syndrome: Pathogenesis, diagnosis, treatment and prognosis," Nat. Rev. Neurol., vol. 10, no. 8, pp. 469-482, 2014, https://doi.org/10. 1038/nrneurol.2014.121.

114. S. Kuwabara et al., "IgG anti-GM1 antibody is associated with reversible conduction failure and axonal degeneration in GuillainBarre syndrome," Ann. Neurol., vol. 44, no. 2, pp. 202-208, 1998, https://doi.org/10.1002/ana.410440210.

115. H. J. Willison, J. Veitch, G. Paterson, and P. G. E. Kennedy, "Miller Fisher syndrome is associated with serum antibodies to GQ1b ganglioside," J. Neurol. Neurosurg. Psychiatry, vol. 56, no. 2, pp. 204-206, 1993, https://doi.org/10.1136/jnnp.56.2.204.

116. D. M.Green, "Advances in the management of Guillain-Barré Syndrome," Curr. Neurol. Neurosci. Rep., vol. 2, pp. 541-548, 2002, https://doi.org/10.12688/f1000research.15834.1.

117. K. Paparounas, G. M. O’Hanlon, C. P. O’Leary, E. G. Rowan, and H. J. Willison, "Anti-ganglioside antibodies can bind peripheral nerve nodes of Ranvier and activate the complement cascade without inducing acute conduction block in vitro," Brain, vol. 122, no. 5, pp. 807-816, 1999, https://doi.org/10.1093/brain/ 122.5.807.

118. N. Yuki et al., "Animal model of axonal Guillain-Barré syndrome induced by sensitization with GM1 ganglioside," Ann. Neurol., vol. 49, no. 6, pp. 712-720, 2001, https://doi.org/10.1002/ana.1012.

119. K. Susuki et al., "Anti-GM1 antibodies cause complementmediated disruption of sodium channel clusters in peripheral motor nerve fibers," J. Neurosci., vol. 27, no. 15, pp. 3956-3967, 2007, https://doi.org/10.1523/JNEUROSCI.4401-06.2007.

120. P. Asthana, G. Zhang, K. A. Sheikh, and C. Him Eddie Ma, "Heat shock protein is a key therapeutic target for nerve repair in autoimmune peripheral neuropathy and severe peripheral nerve injury," Brain. Behav. Immun., 2020, https://doi.org/10.1016/j. bbi.2020.08.020.

121. L. Appeltshauser, "Anti-paranodal antibodies and IgG subclasses in acute autoimmune neuropathy," Neurol. Neuroimmunol. Neuroinflammation, 2020.

122. S. Sawai et al., "Moesin is a possible target molecule for cytomegalovirus-related Guillain-Barré syndrome," Neurology, vol. 83, no. 2, pp. 113-117, 2014, https://doi.org/10.1212/WNL. 0000000000000566

123. K. Yonekura et al., "Prevalence of anti-heat shock protein antibodies in cerebrospinal fluids of patients with Guillain-Barré syndrome," J. Neuroimmunol., vol. 156, no. 1-2, pp. 204-209, 2004, https://doi.org/10.1016/j.jneuroim.2004.07.017.

124. G. Helgeland, A. Petzold, J. M. Hoff, N. E. Gilhus, G. T. Plant, and F. R. Romi, "Anti-Heat Shock Protein 70 antibody levels are increased in myasthenia gravis and Guillain-Barré syndrome," 
J. Neuroimmunol., vol. 225, no. 1-2, pp. 180-183, 2010, https:// doi.org/10.1016/j.jneuroim.2010.04.024.

125. J. M. Vallat et al., "Antibody- and macrophage-mediated segmental demyelination in chronic inflammatory demyelinating polyneuropathy: clinical, electrophysiological, immunological and pathological correlates," Eur. J. Neurol., vol. 27, no. 4, pp. 692-701, 2020, https://doi.org/10.1111/ene.14133.

126. G. M. McKhann, J. W. Griffin, D. R. Cornblath, E. D. Mellits, R. S. Fisher, and S. A. Quaskey, "Plasmapheresis and guillainbarré syndrome: Analysis of prognostic factors and the effect of plasmapheresis," Ann. Neurol., vol. 23, no. 4, pp. 347-353, 1988, https://doi.org/10.1002/ana.410230406.

127. A. El and T. Provost, "Guillain-Barre syndrome with high- dose gammaglobulin," no. October, pp. 1639-1642, 1988.

128. N. Shahrizaila, H. C. Lehmann, and S. Kuwabara, "GuillainBarré syndrome.," Lancet (London, England), vol. 6736, no. 21, 2021, https://doi.org/10.1016/S0140-6736(21)00517-1.

129. S. Liu, C. Dong, and E. E. Ubogu, "Immunotherapy of GuillainBarré syndrome," Hum. Vaccines Immunother., vol. 14, no. 11, pp. 2568-2579, 2018, https://doi.org/10.1080/21645515.2018.1493415.

130. R. Jc et al., "Plasma exchange for Guillain-Barré syndrome ( Review ) Plasma exchange for Guillain-Barré syndrome," no. 4, 2009.

131. M. B. Islam et al., "Small volume plasma exchange for GuillainBarré syndrome in resource poor settings: A safety and feasibility study," Pilot Feasibility Stud., vol. 3, no. 1, pp. 6-12, 2017, https://doi.org/10.1186/s40814-017-0185-0.

132. F. G. A. Van Der Meché, P. I. M. Schmitz, and D. G.-B. syndrome Group, "A randomized trial comparing intravenous immune globulin and plasma exchange in Guillain-Barré syndrome," N. Engl. J. Med., vol. 326, no. 10, pp. 653-657, 1992.

133. R. A. C. Hughes, "Randomised trial of plasma exchange, intravenous immunoglobulin, and combined treatments in GuillainBarre syndrome," Lancet, vol. 349, no. 9047, pp. 225-230, 1997, https://doi.org/10.1016/S0140-6736(96)09095-2.

134. R. A. Hughes, A. V Swan, and P. A. van Doorn, "Intravenous immunoglobulin for Guillain-Barré syndrome," Cochrane Database Syst. Rev., no. 9, 2010, https://doi.org/10.1002/14651858. cd002063.pub4.

135. K. Kuitwaard et al., "Pharmacokinetics of intravenous immunoglobulin and outcome in Guillain-Barré syndrome," Ann. Neurol., vol. 66, no. 5, pp. 597-603, 2009, https://doi.org/10.1002/ ana.21737.

136. C. Verboon et al., "Current treatment practice of Guillain-Barré syndrome," Neurology, vol. 93, no. 1, pp. E59-E76, 2019, https:// doi.org/10.1212/WNL.0000000000007719.

137. C. Verboon et al., "Original research: Second IVIg course in Guillain-Barré syndrome with poor prognosis: The nonrandomised ISID study," J. Neurol. Neurosurg. Psychiatry, vol. 91, no. 2, pp. 113-121, 2020, https://doi.org/10.1136/ jnnp-2019-321496.

138. C. Walgaard et al., "Second intravenous immunoglobulin dose in patients with Guillain-Barré syndrome with poor prognosis (SID-GBS): a double-blind, randomised, placebo-controlled trial," Lancet Neurol., vol. 20, no. 4, pp. 275-283, 2021, https://doi.org/10.1016/S1474-4422(20)30494-4.

139. E. Nobile-Orazio, "The complement story in Guillain-Barré syndrome: from pathogenesis to therapy," Lancet Neurol., vol.
17, no. 6, pp. 483-485, 2018, https://doi.org/10.1016/S14744422(18)30144-3.

140. R. McGonigal et al., "Anti-GD1a antibodies activate complement and calpain to injure distal motor nodes of Ranvier in mice," Brain, vol. 133, no. 7, pp. 1944-1960, 2010, https:// doi.org/10.1093/brain/awq119.

141. A. I. Davidson et al., "Inhibition of complement in Guillain-Barré syndrome: the ICA-GBS study," J. Peripher. Nerv. Syst., vol. 22, no. 1, pp. 4-12, 2017, https://doi.org/10.1111/jns.12194.

142. S. Misawa et al., "Safety and efficacy of eculizumab in GuillainBarré syndrome: a multicentre, double-blind, randomised phase 2 trial," Lancet Neurol., vol. 17, no. 6, pp. 519-529, 2018, https:// doi.org/10.1016/S1474-4422(18)30114-5.

143. R. Van Koningsveld, P. I. M. Schmitz, F. G. A. Van Der Meché, L. H. Visser, J. Meulstee, and P. A. Van Doorn, "Effect of methylprednisolone when added to standard treatment with intravenous immunoglobulin for Guillain-Barré syndrome: Randomised trial," Lancet, vol. 363, no. 9404, pp. 192-196, 2004, https://doi. org/10.1016/S0140-6736(03)15324-X.

144. R. Takahashi and N. Yuki, "Streptococcal IdeS: Therapeutic potential for Guillain-Barré syndrome," Sci. Rep., vol. 5, pp. 1-6, 2015, https://doi.org/10.1038/srep10809.

145. Y. Wang et al., "IgG-degrading enzyme of Streptococcus pyogenes (IdeS) prevents disease progression and facilitates improvement in a rabbit model of Guillain-Barré syndrome," Exp. Neurol., vol. 291, pp. 134-140, 2017, https://doi.org/10.1016/j.expneurol.2017.02.010.

146. Z. T. Al-Salama, "Imlifidase: First Approval," Drugs, vol. 80, no. 17, pp. 1859-1864, 2020, https://doi.org/10.1007/s40265-020-01418-5.

147. G. Zhang, J. Lin, S. Ghauri, and K. A. Sheikh, "Modulation of IgG-FcRn interactions to overcome antibody-mediated inhibition of nerve regeneration," Acta Neuropathol., vol. 134, no. 2, pp. 321-324, 2017, https://doi.org/10.1007/s00401-017-1730-x.

148. Y. Z. Wang et al., "Macrophage migration inhibitory factor is necessary for the Lipo-oligosaccharide-induced response by modulation of Toll-like receptor 4 in monocytes from GBS patients," J. Neuroimmunol., vol. 257, no. 1-2, pp. 67-75, 2013, https://doi.org/10.1016/j.jneuroim.2013.01.006.

149. I. Jahan et al., "Toll-like receptor-4 299Gly allele is associated with Guillain-Barré syndrome in Bangladesh," Ann. Clin. Transl. Neurol., vol. 6, no. 4, pp. 708-715, 2019, https://doi.org/10.1002/acn3.744.

150. K. K. Nyati et al., "Association of TLR4 Asp299Gly and Thr399Ile polymorphisms with Guillain-Barré syndrome in Northern Indian population," J. Neuroimmunol., vol. 218, no. 1-2, pp. 116-119, 2010, https://doi.org/10.1016/j.jneuroim.2009.10.018.

151. F. Eftimov et al., "231st ENMC International Workshop:: International Standard for CIDP Registry and Biobank, Naarden, The Netherlands, 12-14 May 2017," Neuromuscul. Disord., vol. 28, no. 2, pp. 178-184, 2018, https://doi.org/10.1016/j.nmd.2017.10.009.

152. B. C. Jacobs et al., "International Guillain-Barré Syndrome Outcome Study: protocol of a prospective observational cohort study on clinical and biological predictors of disease course and outcome in Guillain-Barré syndrome," J. Peripher. Nerv. Syst., vol. 22, no. 2, pp. 68-76, Jun. 2017, https://doi.org/10.1111/jns.12209.

Publisher's Note Springer Nature remains neutral with regard to jurisdictional claims in published maps and institutional affiliations. 